\title{
OUTFLOW OBSTRUCTION AFTER THE ARTERIAL SWITCH OPERATION: A MULTIINSTITUTIONAL STUDY
}

William G. Williams, $\mathrm{MD}^{\mathrm{a}}$

Jan M. Quaegebeur, $\mathrm{MD}^{\mathrm{b}}$

John W. Kirklin, $\mathrm{MD}^{\mathrm{c}}$

Eugene H. Blackstone, $\mathrm{MD}^{\mathrm{c}}$

The Congenital Heart Surgeons

Society
Objective: Our objectives were to discover whether outflow obstruction immutably accompanies the arterial switch operation and to identify factors that may decrease its prevalence. Methods: Percutaneous or surgical reintervention for obstruction after an arterial switch was selected as an end point for obstruction. Its risk factors were identified by time-related multivariable analyses of yearly follow-up data from 514 neonates with simple transposition or transposition with ventricular septal defect entering 23 institutions before 15 days of age between January 1, 1985, and March 1, 1989. Results: Sixty-two patients underwent 86 reinterventions for right-sided obstruction ( $83 \%$ free at 10 years) and six for left-sided obstruction ( $98 \%$ free at 10 years). After 2 years, right-sided obstruction occurred at a rate of about $1 \%$ per year and left-sided at a rate of about $0.1 \%$ per year. Right ventricular infundibular or valvular obstruction was associated with the aorta and pulmonary trunk positioned side-by-side, coexisting coarctation, use of prosthetic material in sinus reconstruction, one institution, and earlier institutional experience. Pulmonary trunk or pulmonary artery obstruction was associated with lower birth weight, left coronary artery arising from sinus 2 , coronary explantation away from the transection site, three institutions, and earlier institutional experience. Conclusions: A risk-adjusted base incidence ( $0.5 \%$ per year) of reintervention for right-sided obstruction continues late after operation. It is due in part to congenital variability or abnormality of right ventricular outflow structures and to experience and surgeon variability resulting in suboptimal pulmonary trunk reconstruction. The same sources of variability probably affect the aortic root, but its native characteristics plus higher distending pressure make the base incidence considerably less $(0.1 \%$ per year). (J Thorac Cardiovasc Surg 1997;114:975-90)
From the Department of Cardiovascular Surgery, Hospital for Sick Children, Toronto, Ontario, Canada ${ }^{\mathrm{a}}$; Division of Cardiothoracic Surgery, Columbia-Presbyterian Medical Center, New York, N.Y.'; the Division of Cardiothoracic Surgery, University of Alabama at Birmingham, Birmingham, Ala.c; and The Congenital Heart Surgeons Society.

Supported by yearly contributions from each institution, or its surgeons, in the Congenital Heart Surgeons Society.

Read at the Seventy-seventh Annual Meeting of The American Association for Thoracic Surgery, Washington, D.C., May 4-7, 1997.

Received for publication May 5, 1997; revisions requested July 14, 1997; revisions received August 26, 1997; accepted for publication August 26, 1997.

Address for reprints: William G. Williams, MD, Cardiovascular Surgery, Hospital for Sick Children, 555 University Ave., Toronto, Ontario M5G 1X8, Canada.

Copyright (C) 1997 by Mosby-Year Book, Inc.

$0022-5223 / 97 \$ 5.00+0 \quad \mathbf{1 2 / 6 / 8 5 6 8 2}$
W hether or not right-sided (neopulmonary) and left-sided (neoaortic) outflow obstruction immutably accompanies the arterial switch operation to some degree is unknown, as are factors that may decrease its prevalence. This was studied by using, as an end point, reintervention for outflow obstruction, either percutaneous or surgical, in a multiinstitutional study, and determining the patient, surgical, and institutional experience risk factors associated with it.

\section{Patients and methods}

Patients. A total of 895 neonates (1) with complete transposition of the great arteries (TGA) and (2) admitted to one of 23 institutions before 15 days of age were entered prospectively between January 1, 1985, and 
Table I. Location(s) of right-sided outflow obstruction at the first reintervention after arterial switch operations for simple TGA and TGA with VSD

\begin{tabular}{|c|c|c|}
\hline $\begin{array}{c}\text { Location(s) of right-sided } \\
\text { obstruction }\end{array}$ & $n$ & $\%$ of 62 \\
\hline Proximal only & 7 & $11 \%$ \\
\hline Valvular & 7 & $11 \%$ \\
\hline Isolated & 3 & $4.8 \%$ \\
\hline+ Subvalvular and annular & 4 & $6.5 \%$ \\
\hline Distal only & 39 & $63 \%$ \\
\hline Suture line & 28 & $45 \%$ \\
\hline Isolated & 11 & $18 \%$ \\
\hline$+\mathrm{RPA}$ & 5 (1 death $)$ & $8.1 \%$ \\
\hline + LPA & 3 & $4.8 \%$ \\
\hline + RPA and LPA & $9(1$ death $)$ & $15 \%$ \\
\hline Pulmonary arteries only & 11 & $18 \%$ \\
\hline RPA & 3 & $4.8 \%$ \\
\hline LPA & 3 & $4.8 \%$ \\
\hline RPA and LPA & 5 & $8.1 \%$ \\
\hline Proximal and distal & 12 & $19 \%$ \\
\hline $\begin{array}{c}\text { Subvalvular, suture line, } \\
\text { RPA and LPA }\end{array}$ & 3 & $4.8 \%$ \\
\hline Isolated & 2 & $3.2 \%$ \\
\hline+ Annular & 1 & $1.6 \%$ \\
\hline Annular and suture line & 1 & $1.6 \%$ \\
\hline Valvular and suture line & 6 & $9.7 \%$ \\
\hline Isolated & 1 & $1.6 \%$ \\
\hline+ Subvalvular & 1 & $1.6 \%$ \\
\hline+ Annular & 2 & $3.2 \%$ \\
\hline+ Annular and LPA & 1 & $1.6 \%$ \\
\hline+ RPA and LPA & 1 & $1.6 \%$ \\
\hline Valvular and RPA & 2 & $3.2 \%$ \\
\hline Isolated & 1 & $1.6 \%$ \\
\hline+ LPA & 1 & $1.6 \%$ \\
\hline Unknown & 4 & $6.5 \%$ \\
\hline Total & 62 & \\
\hline
\end{tabular}

$L P A$, Left pulmonary artery; $R P A$, right pulmonary artery.

March 1, 1989, into a multiinstitutional study conducted by the Congenital Heart Surgeons Society (CHSS), as previously detailed. ${ }^{1-4}$ An arterial switch operation was performed in 514 of the 846 patients (one additional operation since the last report ${ }^{4}$ ) with either simple TGA $(n=452)$ or TGA and ventricular septal defect (VSD) $(n=62)$ and form the study group.

Follow-up and data. Cross-sectional patient follow-up was conducted yearly in the fashion previously described ${ }^{4}$; the information for this study was gathered through calendar year 1995. Mean follow-up among the 421 survivors was $7.6 \pm 1.31$ years, with $90 \%$ followed up for 6.3 years or longer and $10 \%$ for 9.25 years or longer. Follow-up information was incomplete in 1995 in 26 patients, and the information from the time of last contact was used; in 11 of the 26, this was the information through 1994.

The methods of clinical data compilation and storage have been detailed previously. They included collecting values for variables specific to the patient (demography, cardiac morphology, coexisting cardiac and noncardiac
Table II. Types of procedures directed against rightsided outflow obstruction performed during the first reintervention after arterial switch operations for simple TGA and TGA with VSD

\begin{tabular}{|c|c|c|}
\hline Procedure & $n$ & $\%$ of 62 \\
\hline Surgical & 34 & $55 \%$ \\
\hline Patch enlargement of PT & 6 & $9.7 \%$ \\
\hline $\begin{array}{l}\text { Patch enlargement of PT and } \\
\text { RPA }\end{array}$ & 2 & $3.2 \%$ \\
\hline $\begin{array}{l}\text { Patch enlargement of PT and } \\
\text { LPA }\end{array}$ & 2 & $3.2 \%$ \\
\hline $\begin{array}{l}\text { Patch enlargement of PT, RPA, } \\
\text { and LPA }\end{array}$ & 7 (1 death) & $11 \%$ \\
\hline $\begin{array}{l}\text { Patch enlargement of RPA } \\
\text { and LPA }\end{array}$ & 1 & $1.6 \%$ \\
\hline $\begin{array}{l}\text { Valvotomy }+ \text { patch enlargement } \\
\text { of PT }\end{array}$ & 2 & $3.2 \%$ \\
\hline $\begin{array}{l}\text { Valvotomy }+ \text { patch enlargement } \\
\text { of PT and RPA }\end{array}$ & 1 & $1.6 \%$ \\
\hline Transannular patch & $8^{*}(1$ death $)$ & $13 \%$ \\
\hline $\begin{array}{l}\text { Transannular patch + resection } \\
\text { of RV muscle }\end{array}$ & $4 \dagger$ & $6.5 \%$ \\
\hline Unknown & 1 & $1.6 \%$ \\
\hline Percutaneous & 28 & $45 \%$ \\
\hline Dilation of PT & 6 & $9.7 \%$ \\
\hline Dilation of RPA & 5 & $8.1 \%$ \\
\hline Dilation of LPA & 3 & $4.8 \%$ \\
\hline Dilation of PT and RPA & 1 & $1.6 \%$ \\
\hline Dilation of RPA and LPA & 3 & $4.8 \%$ \\
\hline Valvotomy & 4 & $6.5 \%$ \\
\hline Valvotomy + dilation of PT & 1 & $1.6 \%$ \\
\hline Unknown & 5 & $0.8 \%$ \\
\hline Total & 62 & $100 \%$ \\
\hline
\end{tabular}

$L P A$, Left pulmonary artery; $P T$, pulmonary trunk; $R P A$, right pulmonary artery; $R V$, right ventricle.

*In two, the transannular patch was extended to include the origins of both right and left pulmonary arteries.

In one, the transannular patch was extended to include the origin of the right pulmonary artery.

anomalies, coronary artery pattern (Leiden Convention), great artery relation, and previous procedures), to the operation (level of aortic and pulmonary trunk transection, method of coronary explantation, details of sinus reconstruction and the materials used, if any, and use of the Lecompte maneuver), and to the institution (each institution, date of entry, and operation expressed as the number of years since January 1, 1985, and number of previous arterial switch operations since January 1, 1985, within each institution at the time of the operation).

Because there was insufficient power in the data to identify individual materials used in sinus reconstruction as risk factors, we included as additional variables groups of materials, including autologous pericardium (whether or not glutaraldehyde treated), "synthetic" materials (polytetrafluoroethylene and bovine pericardium), allografts (aortic or pulmonary), and the latter two categories combined as a single variable (see Appendix A).

Reinterventions. All reinterventions, whether percutaneous or surgical, were identified from the follow-up 


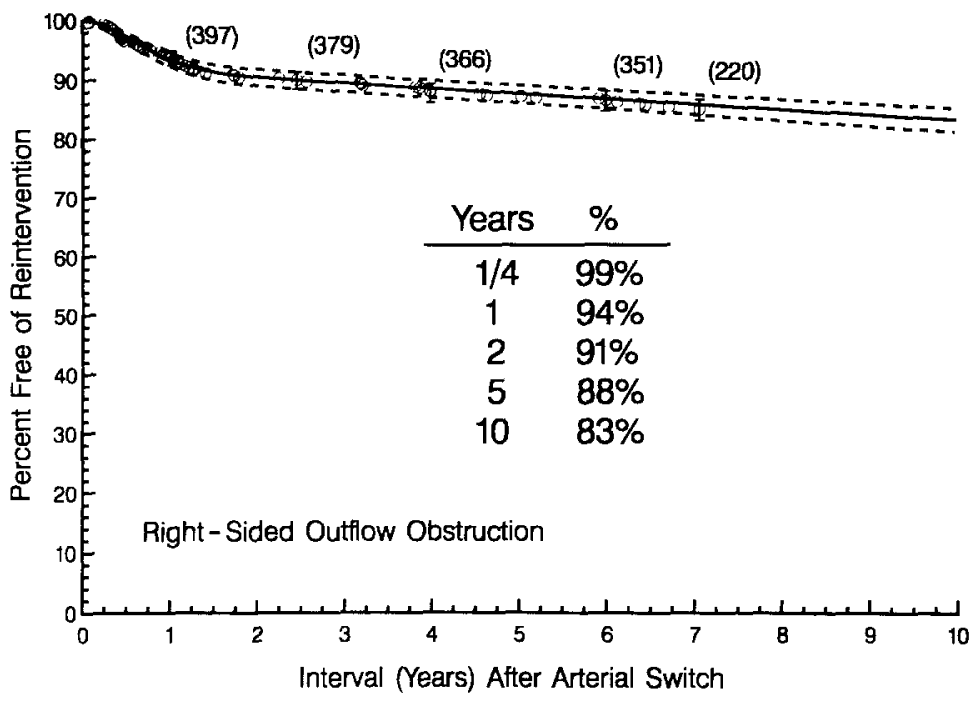

Fig. 1. Time-related percent freedom from reintervention for right-sided obstruction after arterial switch operations for simple TGA and TGA with VSD. Each circle, positioned by the life-table method, represents an event, and the vertical bars represent its $70 \%$ confidence interval, equivalent to 1 standard deviation of the estimate. The numbers in parentheses indicate the numbers of patients still at risk at the time of the estimates. The solid line represents continuous point estimates by parametric hazard function methodology (see Patients and methods) and is enclosed within its dashed $70 \%$ confidence intervals. The table within the graph presents parametric point estimates at the stated intervals after operation.

Table III. Incremental risk factors for right-sided outflow obstruction after arterial switch operations for simple TGA and TGA with VSD, including patient, procedure, and experience variables

\begin{tabular}{|c|c|c|c|c|}
\hline \multirow{3}{*}{$\begin{array}{l}\text { Incremental risk factors for reintervention for } \\
\text { right-sided obstruction }\end{array}$} & \multicolumn{4}{|c|}{ Hazard phase } \\
\hline & \multicolumn{2}{|c|}{ Early } & \multicolumn{2}{|c|}{ Constant } \\
\hline & Coefficient $\pm S D$ & $p$ Value & $\overline{\text { Coefficient }} \pm S D$ & $p$ Value \\
\hline \multicolumn{5}{|l|}{ Patient } \\
\hline Left coronary artery arising from sinus 2 & $1.136 \pm 0.44$ & 0.01 & 一 & - \\
\hline \multicolumn{5}{|l|}{ Procedure } \\
\hline Coronary explant away from transection site & 一 & 一 & $0.7449 \pm 0.46$ & 0.1 \\
\hline $\begin{array}{l}\text { Sinus reconstruction using materials other } \\
\text { than autologous pericardium }\end{array}$ & - & - & $0.9598 \pm 0.46$ & 0.04 \\
\hline \multicolumn{5}{|l|}{ Experience } \\
\hline (Earlier) Date of operation* & $3.185 \pm 0.96$ & 0.0009 & - & - \\
\hline Institution $\mathrm{X}$ & $1.797 \pm 0.49$ & 0.0003 & - & - \\
\hline Institution $\mathrm{Y}$ & $2.263 \pm 0.58$ & $<0.0001$ & - & - \\
\hline Institution Z & - & - & $1.169 \pm 0.48$ & 0.02 \\
\hline Intercepts & -4.166 & & -5.248 & \\
\hline
\end{tabular}

$S D$, Standard deviation. Early phase shaping parameter estimates: $\delta=0 ; \rho=0.9027 ; \nu=-0.4933 ; \mathrm{m}=0$.

* 1 /[Interval (years) since $1 / 1 / 1985-1]^{2}$ inverse squared transformation.

information. Those reinterventions for either right-sided or left-sided obstruction constituted the end point for this study. Time-related freedom from reintervention for obstruction was described both by Kaplan-Meier life-table methodology $y^{5}$ and by parametric multiphase hazard function methodology. ${ }^{6}$

The anatomic localization of obstructive Iesion(s) was identified from echocardiographic, angiographic, and op- erative reports. For the analysis, obstruction of the right ventricular infundibulum, right ventricular-aortic trunk junction, and neopulmonary (morphologic aortic) valve were classified as proximal right-sided outflow obstruction, whereas those occurring in the pulmonary trunk (interpreted as being at the suture line) or in either right or left pulmonary artery were classified as distal (Table I). Inasmuch as proximal and distal right-sided obstruction 


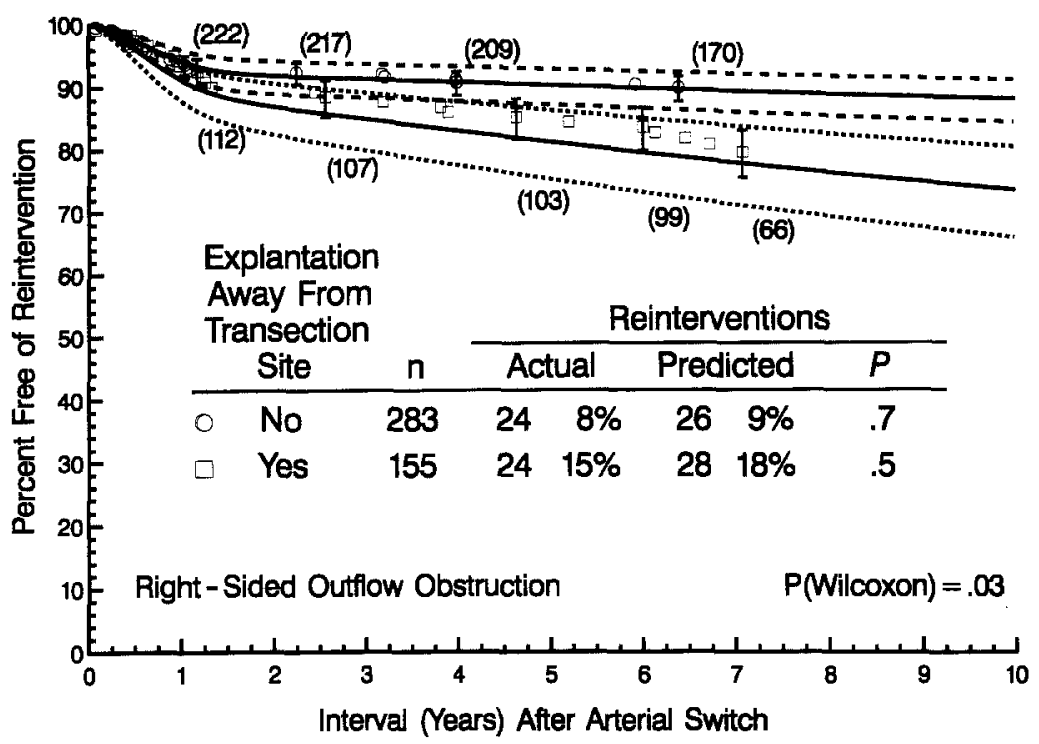

Fig. 2. Freedom from reintervention for right-sided obstruction after arterial switch operations for simple TGA and TGA with VSD, according to whether the coronary artery explantation was adjacent to, or away from, the transection site. As in Fig. 1, the circles and squares and the vertical bars represent life-table estimates based on the actual experience. In contrast to Fig. 1, the solid and dashed lines represent the time-related average of the risk-adjusted percent freedom (and confidence intervals) of each patient obtained by means of the multivariable risk factor equation (Table III). The close correspondence of the two (as also shown in the superimposed table of number of reinterventions) constitutes an internal validation of the parametric method of risk adjustment (see Patients and methods).

often coexisted, the events are both nonmutually exclusive and confounding. Thus, although ordinary competing risks analysis, requiring mutually exclusive events, was not possible, we analyzed proximal obstruction by censoring patients at the time of reintervention for purely distal obstruction, and vice versa for distal obstruction, in the spirit of such an analysis.

The right ventricular-pulmonary artery peak systolic pressure gradient before reintervention was gathered from the catheterization report, operating room measurement, or echocardiographic study performed closest to the procedure. The pressure gradient immediately after reintervention was the one measured in the catheterization laboratory, the operating room, or from a postprocedure echocardiographic study within the same hospitalization as the procedure.

The second reintervention for recurring or residual right-sided obstruction was analyzed from the time of the first reintervention.

Multivariable analyses. Parsimonious equations were developed by entering variables into a sequential set of analyses, as previously described, using (1) only patient variables, (2) patient variables and operative details, and (3) patient, operative, and institutional experience variables. ${ }^{4,7} \mathrm{~A} p$ value of 0.1 was used to retain variables in the final models.

Presentation. The shape of the relation of risk factors to the event is depicted in the form of nomograms, constructed by solving a multivariable equation for a specific set of risk factors. These are accompanied by confidence limits (CL) equivalent to 1 standard deviation (in common with point estimates of all varieties in this paper). Additional depictions were constructed after solving a multivariable equation across time for each patient in the data set, then stratifying the patients according to a stated factor and averaging their individual curves. These depictions are accompanied by stratified life-table estimates for comparison (so-called internal validation of the multivariable equation) and also by a table of observed number of events compared with predicted number from the analysis. 8,9

\section{Results}

Reintervention for right-sided obstruction. Among the 514 patients with simple TGA or TGA with VSD undergoing the arterial switch operation, 62 had reintervention for right-sided obstruction within the period of follow-up. Of these, 34 were surgical and 28 percutaneous procedures (Table II). Risk-unadjusted freedom from reintervention for right-sided obstruction was $94 \%, 88 \%$, and $83 \%$ at 1,5 , and 10 years, respectively (Fig. 1). The instantaneous risk of such reinterventions (hazard function) rose to a peak at 9 months, then declined to merge with a constant, unchanging risk of $1 \%$ per year by about 2 years. 


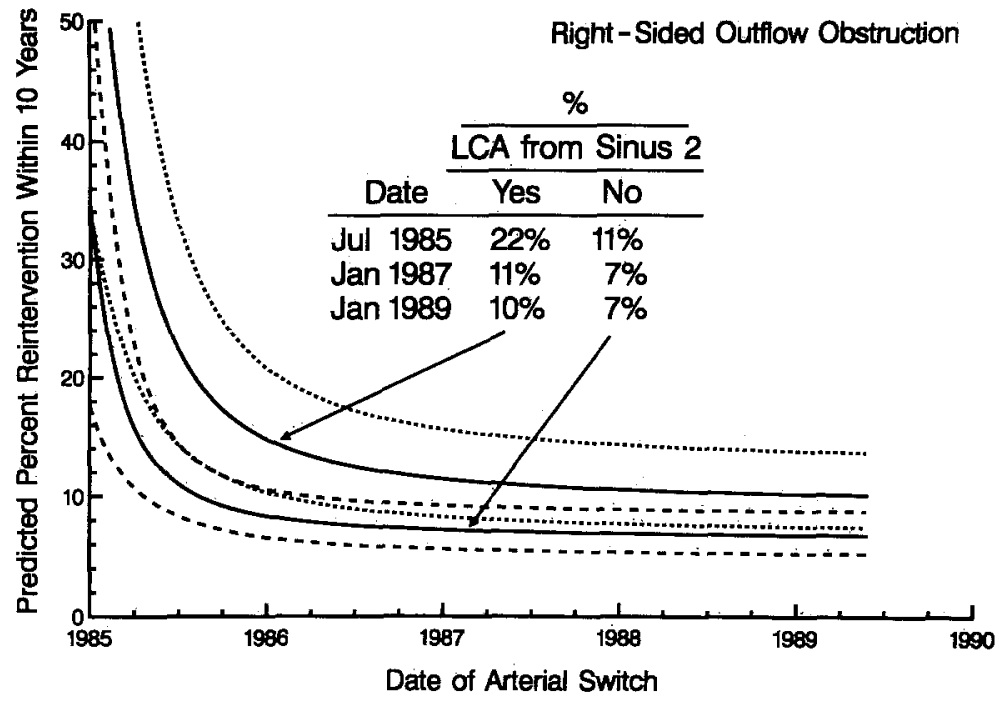

Fig. 3. Graph showing the risk-adjusted probability (expressed as percent) by 10 years of reintervention for right-sided obstruction after arterial switch operations for simple TGA and TGA with VSD, according to the date of operation (horizontal axis) and the coronary pattern (isobars). The depiction is a nomogram of a specific solution of the multivariable equation (Table III) for which "no" is the value for coronary explant away from transection site and "no" is the value for Institutions X, Y, and Z; thus, it is applicable to the typical patient in the study. $L C A$, Left coronary artery.

The magnitude of the pressure gradient between the right ventricle and pulmonary arteries immediately before the reintervention was greater for those undergoing a surgical rather than a percutaneous procedure (see Appendix B).

Risk factors for reintervention for right-sided obstruction. Patient, procedure, and institutional experience risk factors for reintervention for rightsided obstruction are given in Table III. These included the early risk associated with the unusual coronary pattern of the left coronary artery arising from sinus 2, whether intramural or not, and the late risk of coronary explant away from the transection site (Fig. 2), institutional experience, and earlier date of operation. In addition, sinus reconstruction using materials other than pericardium increased the late risk of right-sided obstruction.

The risk-adjusted base prevalence of right-sided obstruction after the arterial switch operation was about $5 \%$ to $10 \%$ within 10 years, corresponding to a constant hazard base incidence of $0.5 \%$ per year (CL $0.4 \%$ to $0.8 \%$ ), estimated from a nomogram of the influence of date of operation, setting high-risk for reintervention institutions and coronary explant away from transection site, and sinus reconstruction using materials other than autologous pericardium to "no" (Fig. 3).
Table IV. Incremental risk factors for proximal right-sided outflow obstruction after arterial switch operations for simple TGA and TGA with VSD

\begin{tabular}{|c|c|c|}
\hline \multirow{3}{*}{$\begin{array}{c}\text { Incremental risk factors } \\
\text { for reintervention for proximal } \\
\text { right-sided obstruction }\end{array}$} & \multicolumn{2}{|c|}{ Single hazard phase } \\
\hline & \multicolumn{2}{|l|}{ Eariy } \\
\hline & \multicolumn{2}{|c|}{ Coefficient $\pm S D p$ Value } \\
\hline \multicolumn{3}{|l|}{ Patient } \\
\hline $\begin{array}{l}\text { Aorta side-by-side with, and to the } \\
\text { right of, pulmonary artery }\end{array}$ & $2.093 \pm 0.70$ & 0.003 \\
\hline Coexisting coarctation of the aorta & $1.734 \pm 0.58$ & 0.003 \\
\hline \multicolumn{3}{|l|}{ Procedure } \\
\hline Sinus reconstruction with PTFE & $1.841 \pm 0.71$ & 0.01 \\
\hline \multicolumn{3}{|l|}{ Experience } \\
\hline (Earlier) Date of operation* & $3.134 \pm 1.43$ & 0.03 \\
\hline Institution $\mathrm{X}$ & $1.210 \pm 0.52$ & 0.02 \\
\hline Intercept & -4.964 & \\
\hline
\end{tabular}

$S D$, Standard deviation; $P T F E$, polytetrafluoroethylene. Early phasé sháping parameter estimates: $\delta=0 ; \rho=0.9692 ; \nu=1 ; \mathrm{m}=0$.

${ }^{*} 1 /$ [nterval (years) since 1/1/1985 - 1] inverse transformation.

In the sequence of multivariable analyses (available from the authors by request), one additional risk factor was identified that dropped out of the analysis when institutional variables were entered: sinus reconstruction using untreated pericardium (early hazard phase). Since method of sinus recon- 


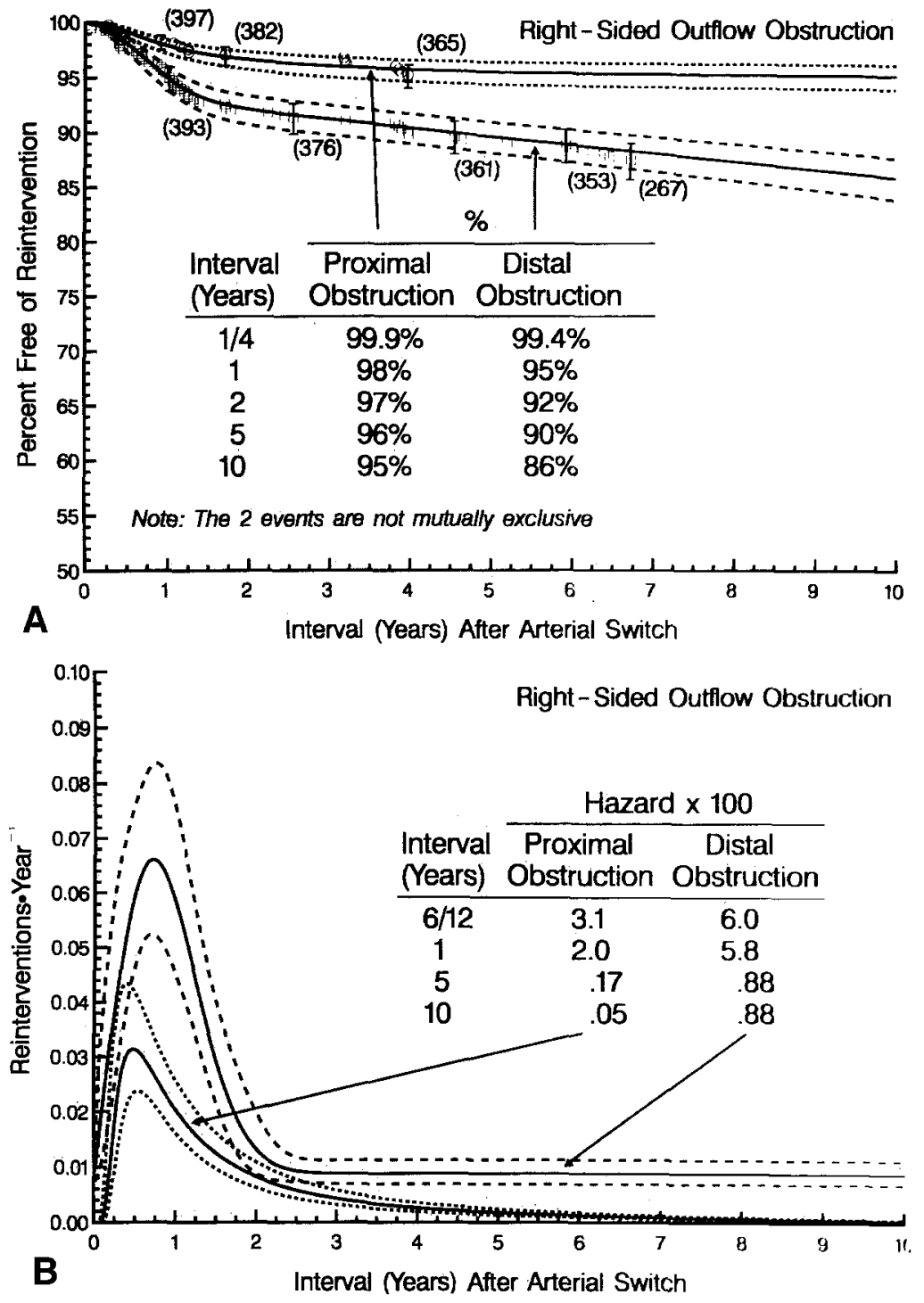

Fig. 4. Freedom from reintervention for proximal and distal right-sided obstruction after arterial switch operations for simple TGA and TGA with VSD. A, Time-related percent free of reintervention. In contrast to the format of Fig. 1, two different events are superimposed on the same graph to aid in their comparison. In fact, on each curve the number of patients is the total group, $n=514$. Also (see Patients and methods), the events on the two curves are not entirely mutually exclusive, because proximal and distal levels of obstruction often coexisted (see Table I). B, Hazard function (instantaneous risk) for the first reintervention. The hazard functions for the two different events are superimposed for comparison. The continuous point estimates (solid lines), obtained by hazard function methodology, are enclosed within their dashed $70 \%$ confidence limits.

struction was to some extent institution-specific, and the institution was the stronger explanatory variable, we interpret the result to be that it was the institution, not the method of sinus reconstruction, that was the risk factor.

Site of right-sided obstruction. The site of rightsided obstruction was commonly in the pulmonary trunk, presumably at the site of the suture line (see Table I). It often coexisted with stenosis of one or both pulmonary arteries. Proximal sites of obstruction, including subvalvular stenosis in eight children (13\%), commonly coexisted with additional sites of distal obstruction. Freedom from proximal rightsided obstruction was $98 \%, 96 \%$, and $95 \%$ at 1,5 , 


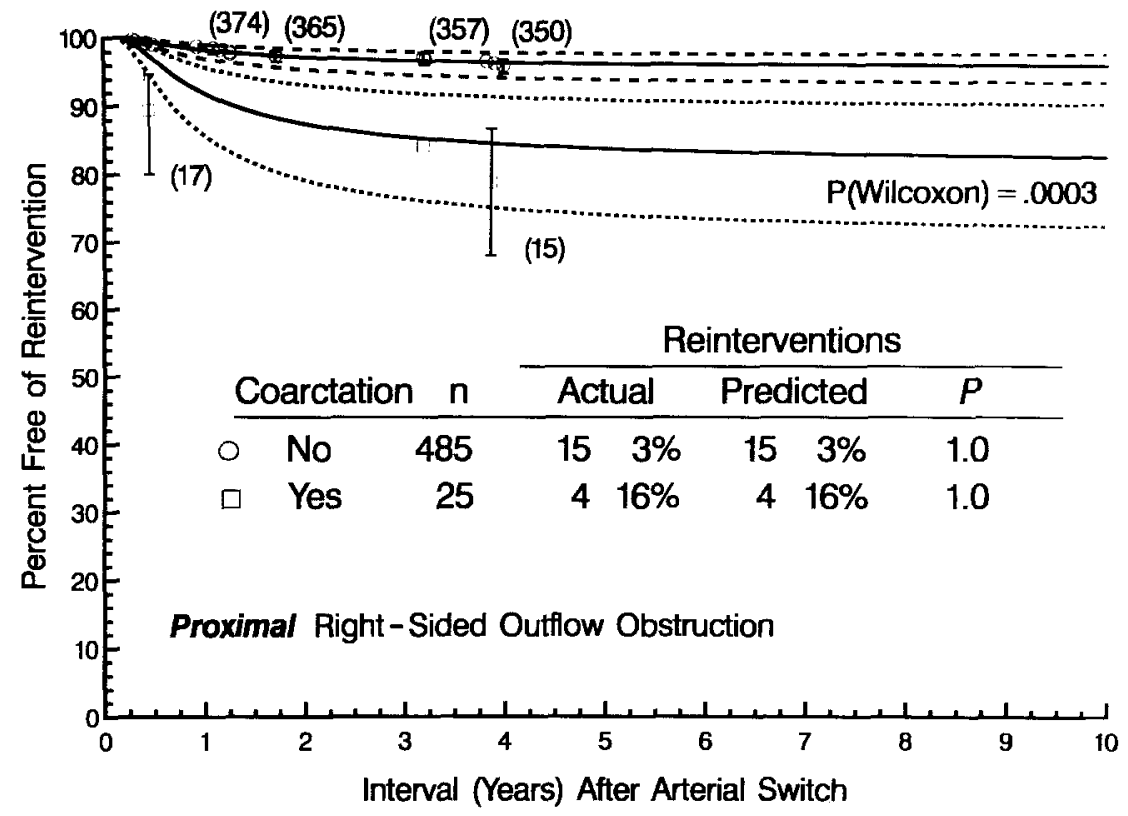

Fig. 5. Freedom from reintervention for proximal right-sided obstruction after arterial switch operations for simple TGA and TGA with VSD, according to the presence or absence of aortic coarctation. The format of the depiction is as in Fig. 2.

and 10 years, respectively; freedom from distal right-sided obstruction was $95 \%, 90 \%$, and $86 \%$ at 1, 5, and 10 years, respectively (Fig. 4, A). The hazard function for proximal obstruction consisted of a single peaking hazard phase, in contrast to the hazard function for distal obstruction that consisted of both an early peaking hazard phase and a constant hazard phase that persisted as long as the patients were followed up (Fig. 4, B).

Risk factors for reintervention for proximal rightsided obstruction. Patient, procedure, and institutional experience risk factors for reintervention for proximal right-sided obstruction are given in Table IV. The prevalence of this event declined rapidly as experience increased for patients without other risk factors, and risk of its occurring approached zero after about 4 to 5 years (Fig. $4, B$ ). Within the CHSS study, virtually all patients received the Lecompte maneuver. Thus it was not possible to investigate the possibility of an interaction between use of a Lecompte maneuver and the side-by-side aortic-pulmonary artery relation. The association of proximal obstruction and the coexistence of aortic coarctation is illustrated in Fig. 5. The use of polytetrafluoroethylene to reconstruct the sinuses, earlier date of operation, and one institution were associated with a greater risk of proximal obstruction.
Risk factors for reintervention for distal rightsided obstruction. Patient, procedure, and institutional experience risk factors for reintervention for distal right-sided obstruction are given in Table V. These risk factors are similar to those for all right-sided reinterventions (see Table III), including the use of nonautologous materials for sinus reconstruction (Fig. 6). Lower birth weight and the left coronary artery arising from sinus 2 or intramural origin increased the risk of obstruction (see Appendix C).

Outcomes after reintervention for right-sided obstruction. Of the 62 children undergoing a reintervention for right-sided obstruction, two died on the day of the operation $(3.2 \%, \mathrm{CL} 1.1 \%$ to $7.5 \%)$. Both children had associated coronary artery ostial stenosis.

Twenty children had one or more subsequent reinterventions (Table VI). Freedom from a second reintervention was $83 \%, 67 \%$, and $62 \%$ at 1,5 , and 10 years after a first reintervention. There was no apparent difference in recurrence prevalence for proximal versus distal obstruction. The chances of a second intervention were greater if the first had been a percutaneous procedure (Fig. 7) and if the pressure gradient was higher after the first intervention (Fig. 8). 


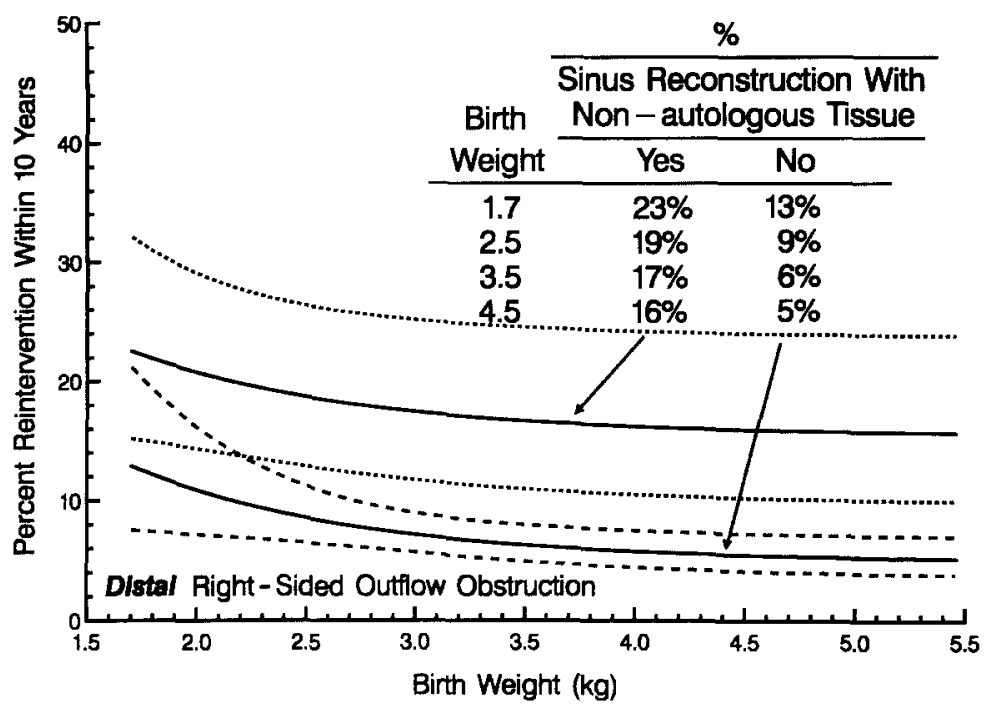

Fig. 6. Graph showing the risk-adjusted probability (expressed as percent) of reintervention for distal right-sided obstruction within 10 years of an arterial switch operation for simple TGA and TGA with VSD, according to birth weight (horizontal axis) and the type of material used in sinus reconstruction (isobars). The depiction is a nomogram of a specific solution of the multivariable equation (Table V) for which "no" is the value for the left coronary arising from sinus 2 or an intramural coronary artery and "no" is the value for institutions $\mathrm{X}, \mathrm{Y}$, and $\mathrm{Z}$.

Table V. Incremental risk factors for distal right-sided outflow obstruction after arterial switch operations for simple TGA and TGA with VSD, including patient, procedure, and experience variables

\begin{tabular}{|c|c|c|c|c|}
\hline \multirow{3}{*}{$\begin{array}{l}\text { Incremental risk factors } \\
\text { for reintervention for distal } \\
\text { right-sided obstruction }\end{array}$} & \multicolumn{4}{|c|}{ Hazard phase } \\
\hline & \multicolumn{2}{|c|}{ Early } & \multicolumn{2}{|c|}{ Constant } \\
\hline & Coefficient $\pm S D$ & $p$ Value & Coefficient $\pm S D$ & p Value \\
\hline \multicolumn{5}{|l|}{ Patient } \\
\hline (Lower) Birth weight (kg) & $-1.024 \pm 0.49$ & 0.04 & - & - \\
\hline Left coronary artery arising from sinus 2 & $0.9216 \pm 0.57$ & 0.1 & - & - \\
\hline Intramural course of coronary artery & - & - & $2.313 \pm 1.02$ & 0.02 \\
\hline \multicolumn{5}{|l|}{ Procedure } \\
\hline $\begin{array}{l}\text { Sinus reconstruction using materials other than } \\
\text { autologous pericardium }\end{array}$ & - & - & $1.194 \pm 0.52$ & 0.02 \\
\hline \multicolumn{5}{|l|}{ Experience } \\
\hline (Earlier) Date of operation* & $3.839 \pm 1.05$ & 0.0003 & - & - \\
\hline Institution $\mathrm{X}$ & $1.350 \pm 0.54$ & 0.01 & - & - \\
\hline Institution Y & $2.327 \pm 0.61$ & 0.0001 & - & - \\
\hline Institution Z & - & - & $1.639 \pm 0.54$ & 0.002 \\
\hline Intercepts & -0.8460 & & -5.278 & \\
\hline
\end{tabular}

$S D$, Standard deviation. Early phase shaping parameter estimates: $\delta=0, \rho=0.8310, v=0.4712, \mathrm{~m}=0$.

*1/[Interval (years) since $1 / 1 / 1985-1]^{2}$ inverse squared transformation.

Reintervention for left-sided obstruction. Six patients underwent a reintervention for left-sided obstruction, consisting of patch angioplasty of the ascending aorta in four and left ventricular fibromyectomy in two. Risk-unadjusted freedom from reintervention for left-sided obstruction was
$99.3 \%, 98.9 \%$, and $98.3 \%$ at 1,5 , and 10 years, respectively (Fig. 9). Its hazard function rose to a peak at 6 months, then fell to merge with a constant, low unchanging risk by about 1 year $(0.1 \%$ per year), approximately one tenth the magnitude of that for right-sided reinterventions. 
The small number of events precluded multivariable analysis.

\section{Discussion}

Critique of the study. Both the uniqueness of the patient population and its limitations as an observational one have been thoroughly delineated. ${ }^{4}$ Pertinent for this study was the fact that it encompassed a unique time period, when institutions were just beginning to have experience with the arterial switch operation. This led to close scrutiny of many of these children, a large number of whom underwent routine 1-year cardiac catheterization assessment. However, the technical details of the arterial switch were not standardized across institutions, leading both to fortuitous heterogeneity and, simultaneously, confounding of technique with institutional variance. A specific lack of variability that limited this study was the routine use within CHSS institutions of the Lecompte maneuver. It was performed in all but 20 patients in this study, two of whom experienced a right-sided event.

Reintervention for outflow obstruction was used as a surrogate end point for outflow obstruction in this study. Further, the time-relatedness of outflow obstruction was assumed to coincide with the timerelatedness of a procedure to treat it. During this era, when surgeons were switching from atrial to arterial operations, the patients tended to be scrutinized by periodic echocardiography or catheterization. Despite the observations made, we were unable in the majority of cases to time the onset of obstruction. The indication for reintervention based on these studies varied from center to center, leading to some of the observed institutional differences, and likely varied across the time of follow-up. Thus the event reintervention is simply an objective, reliably timed surrogate for outflow obstruction and may both overestimate and underestimate its incidence and timing to an unknown extent.

The location of obstructive lesions was often multiple. This led to reinterventions on obstructive lesions that might not have required reintervention if they had occurred singly. It also reduced the specificity of our analyses to identify factors uniquely contributing to obstruction in one locality, as well as lowering the sensitivity of our analysis by increasing the "background noise" contributed by multiple sites of obstruction.

Outflow obstruction accompanying the arterial switch operation. Although risk factor analyses were able to identify both understandable and clin-
Table VI. Reinterventions subsequent to the first for right-sided outflow obstruction at the first reintervention after arterial switch operations for simple TGA and TGA with VSD

\begin{tabular}{|c|c|c|}
\hline Second reintervention & $n$ & $\%$ or 20 \\
\hline Surgical procedure & 15 & $75 \%$ \\
\hline Patch enlargement of PT & 2 & \\
\hline Patch enlargement of PT and RPA & 2 & $10 \%$ \\
\hline Patch enlargement of PT and LPA & 2 & $10 \%$ \\
\hline $\begin{array}{l}\text { Patch enlargement of PT, RPA } \\
\text { and LPA }\end{array}$ & 1 & $5 \%$ \\
\hline $\begin{array}{l}\text { Patch enlargement of RPA and } \\
\text { LPA }\end{array}$ & 2 & $10 \%$ \\
\hline $\begin{array}{l}\text { Valvotomy }+ \text { resection of RV } \\
\text { muscle }+ \text { patch enlargement of } \\
\text { PT }\end{array}$ & 1 & $5 \%$ \\
\hline $\begin{array}{l}\text { Valvotomy + patch enlargement of } \\
\text { PT, RPA and LPA }\end{array}$ & 1 & $5 \%$ \\
\hline Transannular patch & 3 & $15 \%$ \\
\hline Unknown & 1 & $5 \%$ \\
\hline Percutaneous procedure & 5 & $25 \%$ \\
\hline Dilation of RPA and LPA & 2 & $10 \%$ \\
\hline Dilation of LPA & 1 & $5 \%$ \\
\hline $\begin{array}{l}\text { Dilation and stenting of RPA and } \\
\text { LPA }\end{array}$ & 1 & $5 \%$ \\
\hline Unknown & 1 & $5 \%$ \\
\hline Total & 20 & \\
\hline Third reintervention & $n$ & $\%$ of 3 \\
\hline Surgical procedure & 1 & $33 \%$ \\
\hline Patch enlargement of PT & 1 & $33 \%$ \\
\hline Percutaneous procedure & 2 & $67 \%$ \\
\hline Dilation of RPA and LPA & 1 & $67 \%$ \\
\hline Dilation of LPA & 1 & $67 \%$ \\
\hline Total & 3 & \\
\hline Fourth reintervention & $n$ & $\%$ of 1 \\
\hline Surgical procedure & 1 & $100 \%$ \\
\hline $\begin{array}{l}\text { Patch enlargement of RPA and } \\
\text { LPA }\end{array}$ & 1 & $100 \%$ \\
\hline Total & 1 & $100 \%$ \\
\hline
\end{tabular}

ically relevant subgroups of patients at higher risk of obstruction, these did not account for all obstructions. We may have overlooked pertinent other factors, or data may not be available, that contribute to obstruction. Within this limitation, we have identified a base incidence of obstruction that appears to continue immutably throughout at least the childhood of patients who have undergone the arterial switch operation.

Right-sided obstruction. Apparently mild and overlooked congenital variability of the right ventricular outflow tract and the outflow (morphologic aortic) valve occasionally yield anatomy that increases the prevalence of obstruction, albeit more 


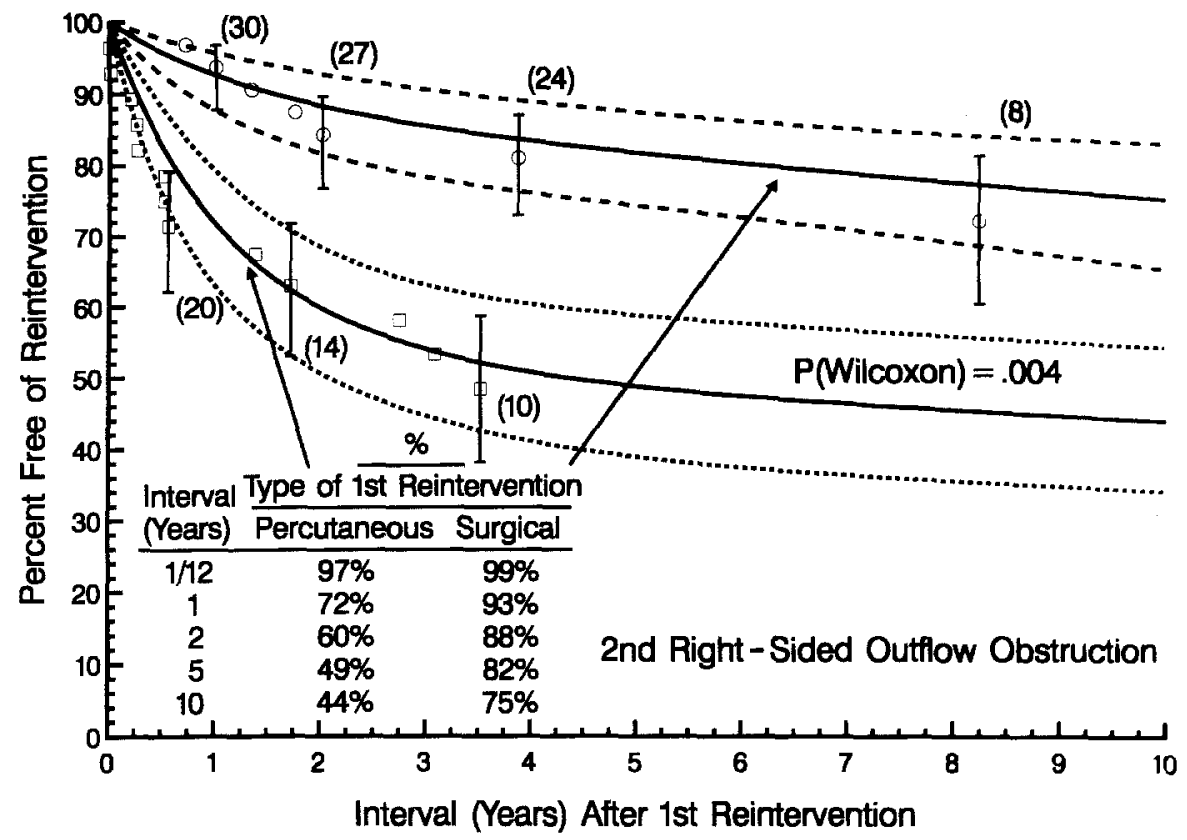

Fig. 7. Freedom from a second reintervention for right-sided obstruction after arterial switch operations for simple TGA and TGA with VSD, according to whether the first reintervention had been a percutaneous or a surgical procedure. As in Fig. 1, the circles and squares and the vertical bars represent life-table estimates, and solid and dashed lines represent parametric estimates.

proximal. Specifically, the known relation association of hypoplasia of left ventricular structures with ordinary coarctation of the aorta is reflected, in transposition, with hypoplasia of the right ventricular infundibulum, right ventricular-aortic junction, and valve. The morphologic variants with the potential for subvalvular right ventricular obstruction were reported by Boyadjiev and associates ${ }^{10}$ and include obstruction of the aortic arch, an observation in keeping with our finding that coarctation and side-by-side great arteries increase the risk of obstruction. One would anticipate that an associated VSD with the attendant risk of infundibular malalignment would increase the risk of obstruction, but we found no difference in prevalence of obstruction in simple TGA versus TGA with VSD.

Hypoplasia of the morphologic aortic valve may be evident both before and after the arterial switch operation. ${ }^{10 a, 11}$ Nakanishi and coworkers ${ }^{11}$ reported that $18 \%$ of their patients had either a small anulus before the arterial switch operation or no significant growth of the neopulmonary valve after the operation. They found that patients with a VSD had a smaller anulus, but in our analysis, the presence of a VSD had no influence on the development of right-sided obstruction. Nogi and colleagues (unpublished data) identified right ventricular outflow obstruction in 32 of 136 patients and noted a correlation of neopulmonary valve stenosis $(n=13)$ to distal obstruction. Others have noted pulmonary valve stenosis in $4 \%$ to $9 \%$ of their series.

The prevalence of right-sided obstruction decreased over time (see Fig. 3), as it has in some 2-14 $^{12-2}$ but not all series. ${ }^{15,16}$ However, there is an immutable incidence of distal pulmonary artery obstruction over the entire 10-year follow-up of these children. We speculate that its incidence will increase as these children enter the rapid somatic growth phase of their adolescent years. In contrast to distal obstruction, proximal obstruction appears early, is associated with morphologic substrates (see Fig. 4, B), and its risk approaches zero in later follow-up. Proximal and distal obstruction may occur in the same patient.

When the enlargement of the base of the pulmonary trunk effected by the operation is less, as when coronary explant is away from the transection site or when the left coronary artery comes from sinus 2 , 


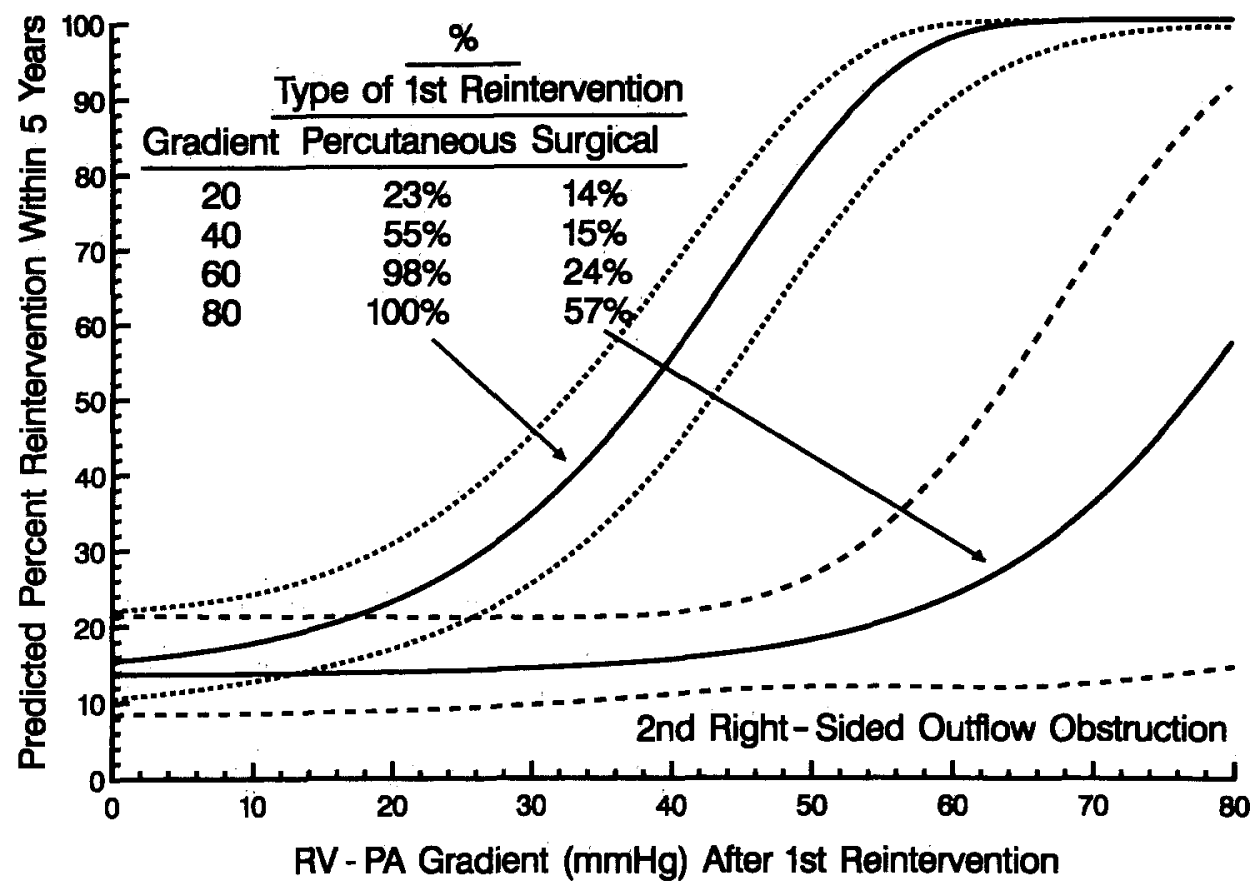

Fig. 8. Graph showing the risk-adjusted probability (expressed as percent) of a second reintervention for right-sided obstruction within 5 years of a first reintervention after an arterial switch operation for simple TGA and TGA with VSD, according to the right ventricular $(R V)$ to pulmonary artery $(P A)$ pressure gradient immediately after the first intervention (horizontal axis) and whether the first intervention had been a percutaneous or surgical procedure (isobars). The depiction is a nomogram of the multivariable equation for second reintervention in which the coefficient for residual RV-PA pressure gradient after the first reintervention was $0.08607 \pm 0.023(p=0.0002)$ and for a percutaneous procedure at the first reintervention was $3.378 \pm 1.88(p=0.07)$; early hazard phase intercept $=-7.176$, shaping parameter estimates: $\delta=0, \rho=1.763 ; \nu=-1, \mathrm{~m}=0$; constant hazard intercept $=-3.534$.

the prevalence of obstruction distal to the neopulmonary valve is increased (see Fig. 3). Despite this, the risk of reintervention decreased as experience with the operation increased.

Inexperience (earlier date of operation) and surgeon variability may result in a less than optimal pulmonary trunk reconstruction that increases the prevalence of obstruction. Unfortunately, the confounding of institution and the details of coronary artery transfer (see Appendix A) reduce our ability to determine specifically the surgical details that may contribute to the nonspecific institutional effect. However, there is a suggestion in the data, as well as recent reports in the literature, that use of artificial prosthetic material for sinus reconstruction may contribute to the increased prevalence (see Fig. 6). ${ }^{14,17}$

Nearly one third of the children who had reintervention for right-sided obstruction have undergone at least one further reintervention for per- sistent or recurrent obstruction. Although surgical intervention was more successful than percutaneous techniques, only $82 \%$ of the children in whom a surgical procedure was used were free of further reintervention 5 years later (see Fig. 7). If one examined only the residual gradient after reintervention, one might infer that either procedure was equally effective, because the gradients are similar at that time (Appendix B). However, the preprocedure gradients were importantly higher in the surgical group. Thus surgical intervention was, in general, the more effective procedure, and particularly so (data available from the authors) when the gradient was high. The risk factors for further reintervention included the residual gradient after the preceding reintervention; however, for any given level of residual gradient, the chances of requiring another reintervention were higher if it had been a percutaneous procedure. 


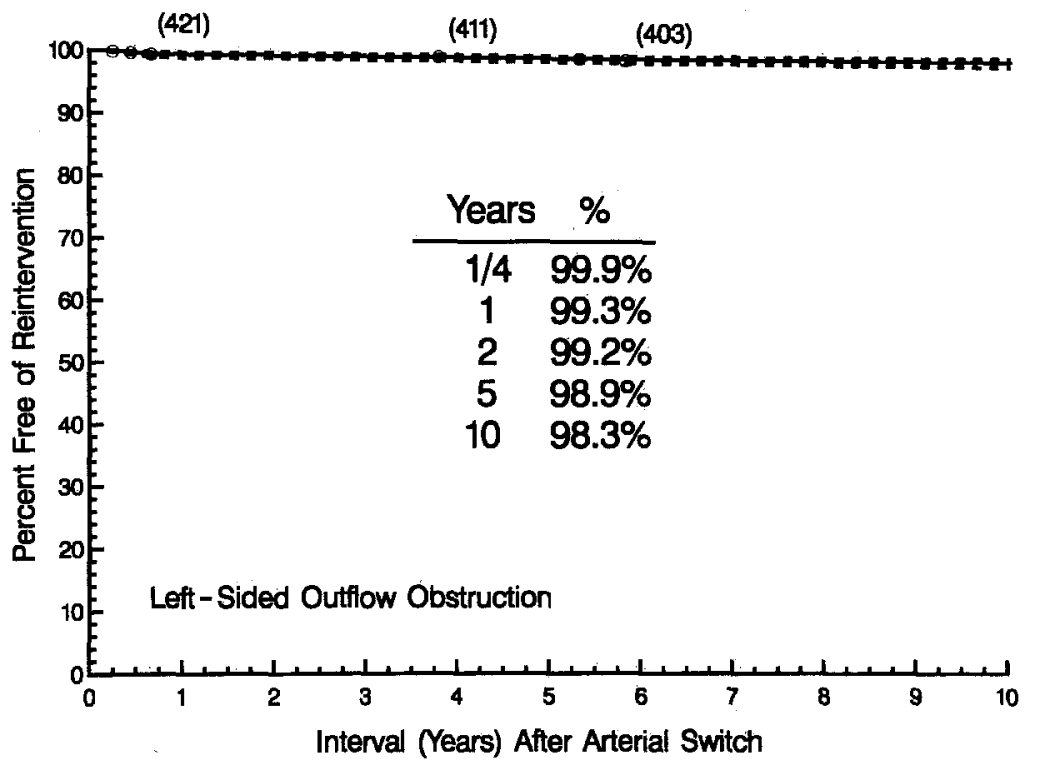

Fig. 9. Time-related freedom from reintervention for left-sided obstruction after arterial switch operations for simple TGA and TGA with VSD. The format of the presentation is as in Fig. 1.

Left-sided obstruction. The same sources of variability that increase the prevalence of right-sided obstruction probably affect the left side. However, it is likely that the native characteristics of the left ventricular outflow tract and the higher distending pressures made the prevalence considerably less. Hourihan and associates ${ }^{18}$ studied the growth of the aortic anastomosis, root, and anulus after the arterial switch and demonstrated that growth of the anastomosis in 50 patients was commensurate with somatic growth, but dilatation of the neoaortic root and anulus appeared to be progressive. ${ }^{18}$ Their observation raises concern regarding the possibility of aortic insufficiency, but, in common with our report, stenosis in the left ventricular outflow tract is uncommon after the arterial switch. It is of interest that in the Mustard era, subvalvular left ventricular outflow tract stenosis developed in $9 \%$ of infants in the interval from birth to intraatrial repair at about age 9 months. $^{19}$

\section{Clinical inferences}

1. The experience to date indicates that a low, immutable risk of right-sided and left-sided obstruction occurs after the arterial switch operation and persists throughout childhood.

2. Some morphologic variants of TGA are more likely to develop proximal right-sided obstruction, and these infants should be assessed carefully with consideration given to enlarging the right-sided outflow at the arterial switch operation.

3. When the enlargement of the base of the pulmonary trunk effected by the operation is less (as when the coronary explant is away from the transection site or when the left coronary artery comes from sinus 2), the prevalence is increased.

4. Inexperience and operator variability may result in a less than optimal pulmonary trunk reconstruction, which increases the prevalence of obstruction. Awareness of the risk factors for right-sided obstruction, including morphologic factors, operative technique, and patch material, should improve future results of the switch operation.

5. Awareness of the frequent failure to alleviate obstruction at reintervention should focus more consideration on potential risk factors leading to that failure. Specifically, when the obstruction is severe, leading to a high pressure gradient, a surgical procedure is likely to be more clinically efficacious and cost-effective than a percutaneous one.

6. The same types of variability that lead to rightsided obstruction probably affect the aortic root, but they are less likely to lead to left-sided obstruction. 
We thank the University of Alabama CHSS Datacentre Staff, Mary Lynn Clark, Robert N. Brown, and Phyllis Newsome for their invaluable assistance in making this study possible.

\section{REFERENCES}

1. Trusler GA, Castaneda AR, Rosenthal A, Blackstone EH, Kirklin JW, The Congenital Heart Surgeons Society. Current results of management in transposition of the great arteries, with special emphasis on patients with associated ventricular septal defect. J Am Coll Cardiol 1987;10:1061-71.

2. Castaneda AR, Trusler GA, Paul MH, Blackstone EH, Kirklin JW, The Congenital Heart Surgeons Society. The early results of treatment of simple transposition in the current era. J Thorac Cardiovase Surg 1988;95:14-28.

3. Norwood WI, Dobell AR, Freed MD, Kirklin JW, Blackstone EH, The Congenital Heart Surgeons Society. Intermediate results of the arterial switch repair. J Thorac Cardiovasc Surg 1988;96:854-62.

4. Kirklin JW, Blackstone EH, Tchervenkov CI, Castaneda AR, The Congenital Heart Surgeons Society. Clinical outcomes after the arterial switch operation for transposition: patient, support, procedural, and institutional risk factors. Circulation 1992;86:1501-15.

5. Kaplan EL, Meier P. Nonparametric estimation from incomplete observations. J Am Stat Assoc 1958;53:457-81.

6. Blackstone EH, Naftel DC, Turner ME Jr. The decomposition of time-varying hazard into phases, each incorporating a separate stream of concomitant information. I Am Stat Assoc 1986;81:615-24.

7. Baskerville JC, Toogood JH. Guided regression modeling for prediction and exploration of structure with many explanatory variables. Technometrics 1982;24:9-17.

8. Ferrazzi P, McGiffin DC, Kirklin JW, Blackstone EH, Bourge RC. Have the results of mitral valve replacement improved? J Thorac Cardiovasc Surg 1986;92:186-97.

9. Blackstone EH, Kirklin JW. Recommendations for prophylactic removal of heart valve prostheses. J Heart Valve Dis 1992;1:3-14.

10. Boyadjiev K, Ho SY, Anderson RH, Lincoln C. The potential for subpulmonary obstruction in complete transposition after the arterial switch procedure. Eur J Cardiothorac Surg 1990;4:214-8.

10a. Nogi S, McCrindle BW, Boutin C, Williams WG, Freedom RM, Benson L. The fate of the neopulmonary valve after the arterial switch operation in neonates. $\mathbf{J}$ Thorac Cardiovasc Surg. In press.

11. Nakanishi T, Momoi N, Satoh M, Yamada M, Terada M, Nakazawa M, Momma K, Imai Y. Growth of the neopulmonary valve annulus after arterial switch operation in transposition of the great arteries. Circulation 1996;94(Suppl):II2731.

12. Wernovsky G, Mayer JE Jr, Jonas RA, Hanley FL, Blackstone $\mathrm{EH}$, Kirklin JW, et al. Factors influencing early and late outcome of the arterial switch operation for transposition of the great arteries. J Thorac Cardiovasc Surg 1995;109:289302.

13. Serraf A, Roux D, Lacour-Gayet F, Touchot A, Bruniaux J, Sousa-Uva $M$, et al. Reoperation after the arterial switch operation for transposition of the great arteries. J Thorac Cardiovasc Surg 1995;110:892-9.
14. Lupinetti FM, Bove EL, Minich LL, Snider AR, Callow LB, Meliones JN, et al. Intermediate-term survival and functional results after arterial repair for transposition of the great arteries. J Thorac Cardiovasc Surg 1992;103: $421-7$.

15. Paillole C, Sidi D, Kachaner J, Planche C, Below JP, Villain $E$, et al. Fate of pulmonary artery after anatomic correction of simple transposition of the great arteries in newborn infants. Circulation 1988;78:870-6.

16. Yasui H, Yonenaga K, Kado H, Nakamura Y, Fusazaki N, Tsuruhara $\mathrm{Y}$, et al. Arterial switch operation for transposition of the great arteries: surgical techniques to avoid complications. J Cardiovasc Surg 1992;33:511-7.

17. Spiegelenbert SR, Hutter PA, van de Wal HJCM, Hitchcock JF, Meijboom EJ, Harinck E. Late re-interventions following arterial switch operations in transposition of the great erteries. Eur J. Cardiothorac Surg 1995;9:7-11.

18. Hourihan M, Colan, SD, Wernovsky G, Maheswari U, Mayer JE Jr, Sanders SP. Growth of the aortic anastomosis, annulus, and root after the arterial switch procedure performed in infancy. Circulation 1993;88:615-20.

19. Dasmahapatra HK, Freedom RM, Moes CAF, Musewe N, Sherret $\mathrm{H}$, Coles JG, et al. Surgical experience with left ventricular outflow tract obstruction in patients with complete transposition of the great arteries and essentially intact ventricular septum undergoing the Mustard operation. Eur J Cardiothorac Surg 1989;3:241-9.

\section{Discussion}

Dr. Frank L. Hanley (San Francisco, Calif.). I congratulate Dr. Williams and his coauthors for an insightful and valuable presentation. It represents the level of quality that all thoracic surgeons have come to expect from studies arising from the CHSS.

This cohort of patients with transposition continues to provide information both of a somewhat theoretical nature, that is, identifying risk factors associated with the development of an unwanted outcome, and of a purely practical nature, that is, surgical reoperation is more effective than balloon dilation when this unwanted outcome occurs.

I have several questions for Dr. Williams. First, what were your reasons for choosing intervention as the end point rather than using a threshold right ventricular outflow tract gradient? This question is especially important given the multiinstitutional nature of this study. For example, I noted that $25 \%$ of the patients receiving a balloon intervention had a gradient of $33 \mathrm{~mm} \mathrm{Hg}$ or less. I suspect that many institutions in this study, especially those that do not have aggressive interventional teams, have significant numbers of patients with similar gradients that did not receive intervention. Also, did you perform any analyses looking at gradient as the end point rather than intervention per se?

Second, you touched on the association between coarctation and subaortic obstruction or proximal obstruction. Did you examine the subaortic infundibular region in the right ventricular outflow tract preoperatively to see whether there are any morphologic markers that might suggest the need for infundibular muscle resection or patching at the time of the original arterial switch? For 
example, was VSD associated with coarctation and subaortic narrowing? Was there anterior malalignment of the conal septum, or was there narrowing of the infundibular lumen in these patients? Interventions at the time of the switch for such problems would suggest that subvalvular or proximal obstruction may not be immutable.

Third, I also noted in the raw data in the manuscript that 19 patients received a "scalloped suture line reconstruction" of the right ventricular outflow tract. I assume this means that no patch material was used at all in these 19 patients. Interestingly, in these 19 patients, no early or late obstruction was found. Also, the confidence limits for these data would suggest that there was no overlap with other groups, suggesting that there may be a significant difference here. Did you examine this particular subgroup separately from the other patients to determine whether absence of patch material in the right ventricular reconstruction was associated with a lack of reintervention?

Dr. C. E. Anagnostopoulos (New York, N.Y.). Few here may remember that Dr. Skinner practiced successful heart surgery and pioneering work on mechanical support during his Hopkins and University of Chicago years. It was at the University of Chicago, where our laboratories were next to each other, that original work on anatomic correction of transposition by arterial switch took place in the early 1970s. Our experimental model involved neither Lecompte maneuver nor pericardium.

My question to the authors echoes a previous remark: Would the incidence of obstruction be less if other autologous tissue, such as rectus sheath, were used for reconstruction?

Dr, Francois LaCour-Gayet (Paris, France). In Paris, we have now performed almost 1000 switches in a single institution, Marie-Lannelongue. Our group has made observations similar to those discussed by this paper, and we definitely agree that the use of fresh autologous pericardium and the way to take out the coronary buttons are extremely important.

As already underlined by Frank Hanley, the most significant factor of right-sided obstruction is the association with coarctation and Taussig-Bing anomaly.
Dr. Williams, do your data not show that association to coarctation was a significant factor.

Dr. Williams. I would like to thank the discussants for their comments and will try to answer them in order.

Dr. Hanley's question: We used reintervention as the criteria for obstruction because it is a finite unarguable end point. Clearly it underestimates the actual incidence of obstruction, but unfortunately we did not have the pressure data on every patient. We did have follow-up information on every patient to know whether or not they had reintervention. Reintervention is an approximation of our estimate of obstruction and unquestionably underestimates the incidence of the problem.

Both Dr. Hanley and Dr. LaCour-Gayet mentioned the problem of obstruction with left-sided lesions. We did find an association both with coarctation and with side-by-side vessels. The Taussig-Bing anomaly was not included in the data set. We looked only at transposition and transposition with VSD. However, side-by-side great vessels and coarctation both led to an incidence of early proximal obstruction. In the case of coarctation, its influence of early obstruction decreased during the era of the study.

Dr. Hanley's usual acute perception picked up the point that the 19 patients in whom no tissue was used to patch these sinuses had no obstruction. That aspect needs to be expanded further by the surgeons who used that technique. Because there were only 19 patients, we did not focus further on this point.

In answer to Dr. Anagnostopoulos' question about the use of other materials, there were also allografts, both pulmonary and aortic. The pulmonary grafts performed somewhat better than the aortic, but the numbers were too small to be definitive. There may well be other tissues that could be used, but the material we had to work with was as I have shown.

Finally, the success and expertise of Dr. LaCour-Gayet's group is well recognized. I think I have addressed his question of the coarctation and association of side-by-side great vessels, which clearly was a factor in predicting obstruction on the right side.

\section{Appendix A: Management of coronary transfer}

Appendix Table A1. Method of coronary explantation used in arterial switch operations for simple TGA and $T G A$ with VSD

\begin{tabular}{|c|c|c|c|c|}
\hline \multirow[b]{2}{*}{ Method of coronary explantation } & \multirow[b]{2}{*}{$n$} & \multicolumn{3}{|c|}{ Reintervention for right-sided outflow obstruction } \\
\hline & & No. & $\%$ & $C L$ \\
\hline From transection site & 283 & 24 & $4.7 \%$ & $3.7 \%-5.8 \%$ \\
\hline Away from transection site & 153 & 24 & $16 \%$ & $13 \%-19 \%$ \\
\hline Combined method & 76 & 14 & $18 \%$ & $14 \%-24 \%$ \\
\hline Coronary transfer with explantation & 6 & 1 & $17 \%$ & $2 \%-46 \%$ \\
\hline Unknown method & 2 & 0 & $0 \%$ & $0 \%-61 \%$ \\
\hline Total & 514 & 62 & $12 \%$ & $10.6 \%-13.7 \%$ \\
\hline
\end{tabular}

$C L, 70 \%$ confidence limits. 
Appendix Table A2. Method of sinus reconstruction in arterial switch operations for simple TGA and TGA with VSD

\begin{tabular}{lrrrr}
\hline \multicolumn{1}{c}{ Method of reconstruction } & & \multicolumn{2}{c}{$\begin{array}{c}\text { Reintervention for } \\
\text { right-sided outflow obstruction }\end{array}$} \\
\hline Individual patches & $n$ & No. & $\%$ & $C L$ \\
Single scalloped patch & 273 & 35 & $13 \%$ & $11 \%-15 \%$ \\
Scalloped suture line & 207 & 25 & $12 \%$ & $10 \%-15 \%$ \\
Combined (one patched, one into suture line) & 19 & 0 & $0 \%$ & $0 \%-10 \%$ \\
Incorporated into transannular patch & 1 & 0 & $0 \%$ & $0 \%-85 \%$ \\
Coronary arteries not explanted & 4 & 0 & $0 \%$ & $0 \%-37 \%$ \\
Unknown method & 6 & 1 & $17 \%$ & $2 \%-46 \%$ \\
Total & 4 & 1 & $25 \%$ & $3 \%-63 \%$ \\
\hline
\end{tabular}

CL, 70\% confidence limits.

Appendix Table A3. Material used in sinus reconstruction in arterial switch operations for simple TGA and TGA with VSD

Reintervention for

right-sided outflow obstruction

\begin{tabular}{|c|c|c|c|c|}
\hline \multirow[b]{2}{*}{ Material } & \multirow[b]{2}{*}{$n$} & & & \\
\hline & & No. & $\%$ & $C L$ \\
\hline None & 25 & 1 & $4 \%$ & $0.5 \%-13 \%$ \\
\hline Untreated autologous pericardium & 250 & 19 & $12 \%$ & $10 \%-15 \%$ \\
\hline Glutaraldehyde-treated autologous pericardium & 182 & 19 & $10 \%$ & $8 \%-13 \%$ \\
\hline Bovine pericardium & 30 & 6 & $20 \%$ & $12 \%-30 \%$ \\
\hline Prosthetic material (PTFE) & 17 & 4 & $24 \%$ & $12 \%-39 \%$ \\
\hline Pulmonary allograft & 5 & 0 & $0 \%$ & $0 \%-32 \%$ \\
\hline Aortic allograft & 4 & 1 & $25 \%$ & $3 \%-63 \%$ \\
\hline Unknown & 1 & 0 & $0 \%$ & $0 \%-85 \%$ \\
\hline Total & 514 & 62 & $12 \%$ & $11.6 \%-13.7 \%$ \\
\hline
\end{tabular}

CL, 70\% confidence limits; PTFE, polytetrafluoroethylene.

Appendix B: Right-sided pressure gradients before and after reintervention

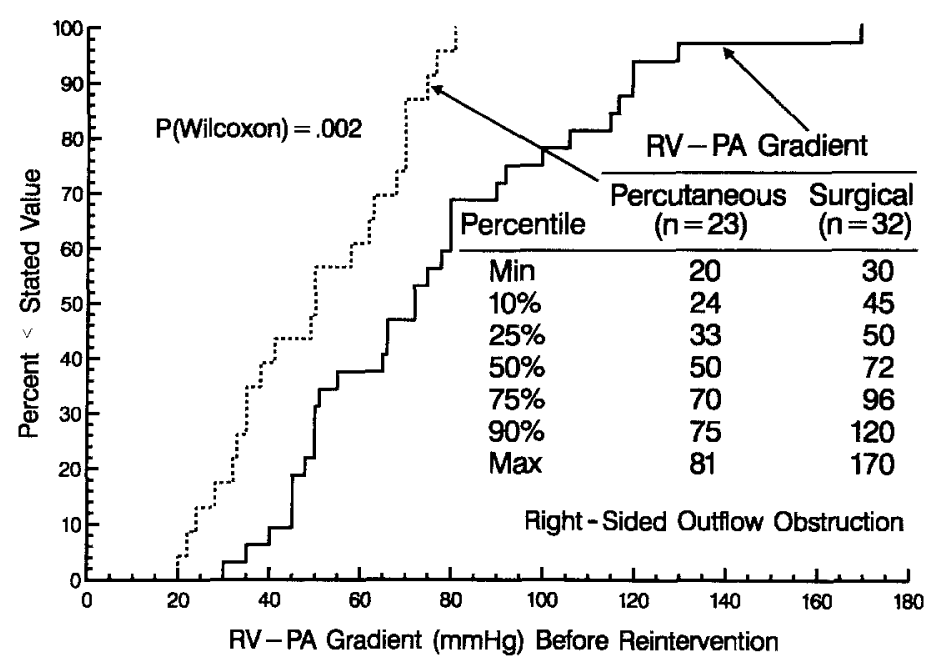

Appendix Fig. B1. Graph of the cumulative frequency distribution of the right ventricular $(R V)$ to pulmonary artery $(P A)$ peak systolic pressure gradient before the first reintervention for right-sided obstruction after arterial switch operations for simple TGA and TGA with VSD, stratified according to whether a surgical procedure (solid line) or a percutaneous procedure (dashed line) was performed. 


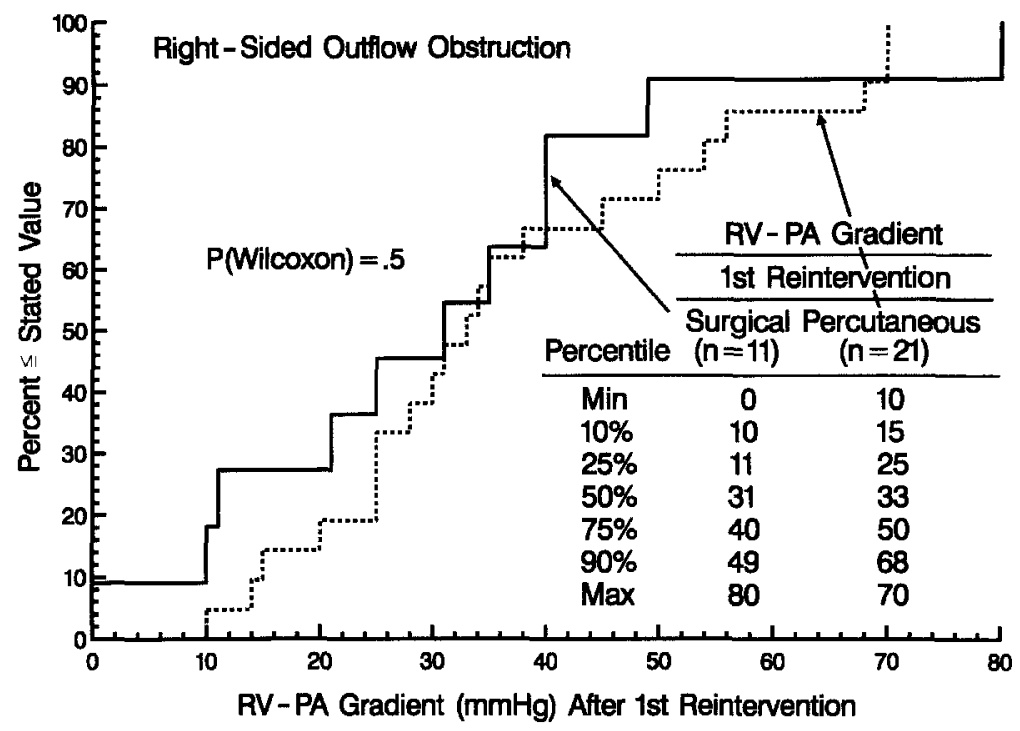

Appendix Fig. B2. Graph of the cumulative frequency distribution of the right ventricular $(R V)$ to pulmonary artery $(P A)$ peak systolic pressure gradient after the first reintervention for right-sided obstruction after arterial switch operations for simple TGA and TGA with VSD, according to whether the procedure was surgical (solid line) or percutaneous (dashed).

\section{Appendix C: Base prevalence of reintervention for distal right-sided obstruction}

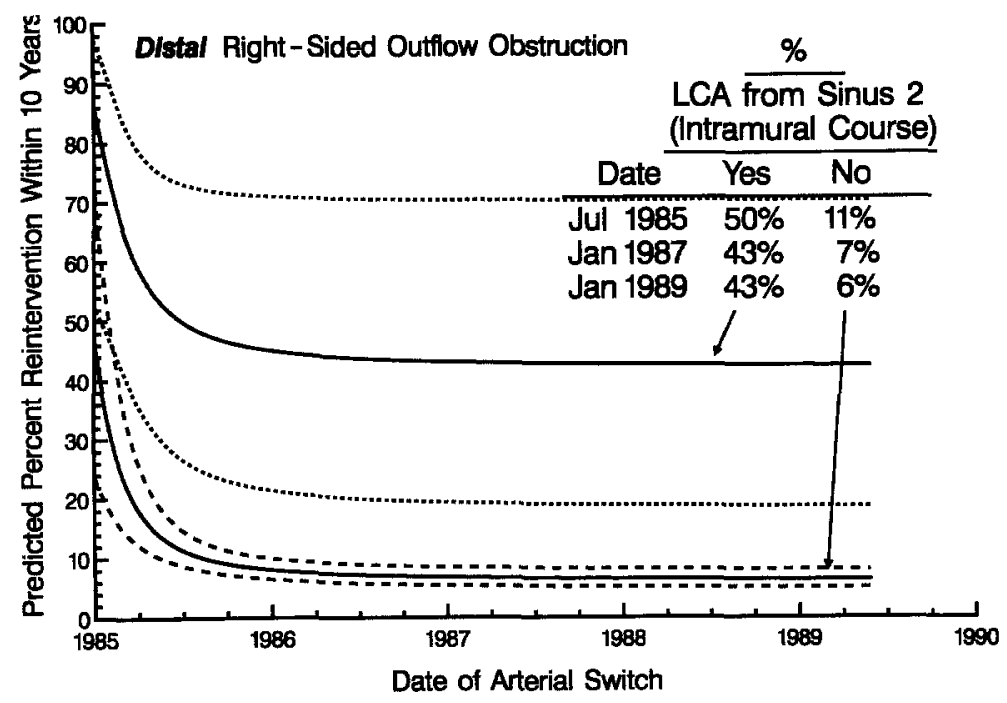

Appendix Fig. C1. Graph showing the risk-adjusted probability (expressed as percent) of reintervention for distal right-sided obstruction within 10 years of an arterial switch operation for simple TGA and TGA with VSD, according to the date of operation (horizontal axis) and whether or not the left coronary artery $(L C A)$ arises from sinus 2 and takes an intramural course. The depiction is a nomogram of a specific solution of the multivariable equation (Table V) for which $3.45 \mathrm{~kg}$ (median) is the birth weight, "no" is the value for the use of patch material other than autogenous pericardium for sinus reconstruction, and "no" is the value for institutions other than $\mathrm{X}, \mathrm{Y}$, and $\mathrm{Z}$. Thus the lower value (4\%) represents the base prevalence of distal right-sided obstruction within 10 years of operation for the typical neonate. 